\title{
Erratum to: Biomass Partitioning during the Life Cycle of Saffron (Crocus sativus L.) Using Regression Models
}

\author{
Mohammad Ali Behdani, Majid Jami Al-Ahmadi, Hamid-Reza Fallahi* \\ (C) Korean Society of Crop Science and Springer 2016 \\ Erratum to: J. Crop Sci. Biotech. 2016 (March) 19(1): 71 76 \\ DOI 10.1007/s12892-015-0082-0
}

\begin{abstract}
On page 72 , in the $7^{\text {th }}$ line of the last paragraph, the following sentence should be replaced and add equation 1 below the paragraph. 'In addition, RMSE (Eq. 1) as an error statistic was used between observed values and predicted ones based on the model (Fallahi et al. 2013): Eq. 1 in which, $n$ is the number of observations, $\mathrm{O} i$ is observed values, and $\mathrm{Si}$ is modelled values at time $i$.' should now read as: 'In addition, RMSE (Eq. 1) as an error statistic was used between observed values and predicted ones based on the model (Fallahi et al. 2013): in which, $n$ is the number of observations, $O i$ is observed values, and $S i$ is modelled values at time $i$.'
\end{abstract}

The online version of the original article can be found under doi: DOI 10.1007/s12892-015-0082-0

\section{Hamid-Reza Fallahi}

Saffron Research Group, University of Birjand, South

Khorasan Province, Birjand, Iran

E-mail: Hamidreza.fallahi@birjand.ac.ir

Tel: +989363574026

$$
R M S E=\sqrt{\frac{1}{\mathrm{n}} \sum_{i=1}^{n}\left(O_{i}-S_{i}\right)^{2}} \text { Eq. } 1
$$

Also, figures 6 and 10 should be changed. The updated figures are shown in this erratum. 


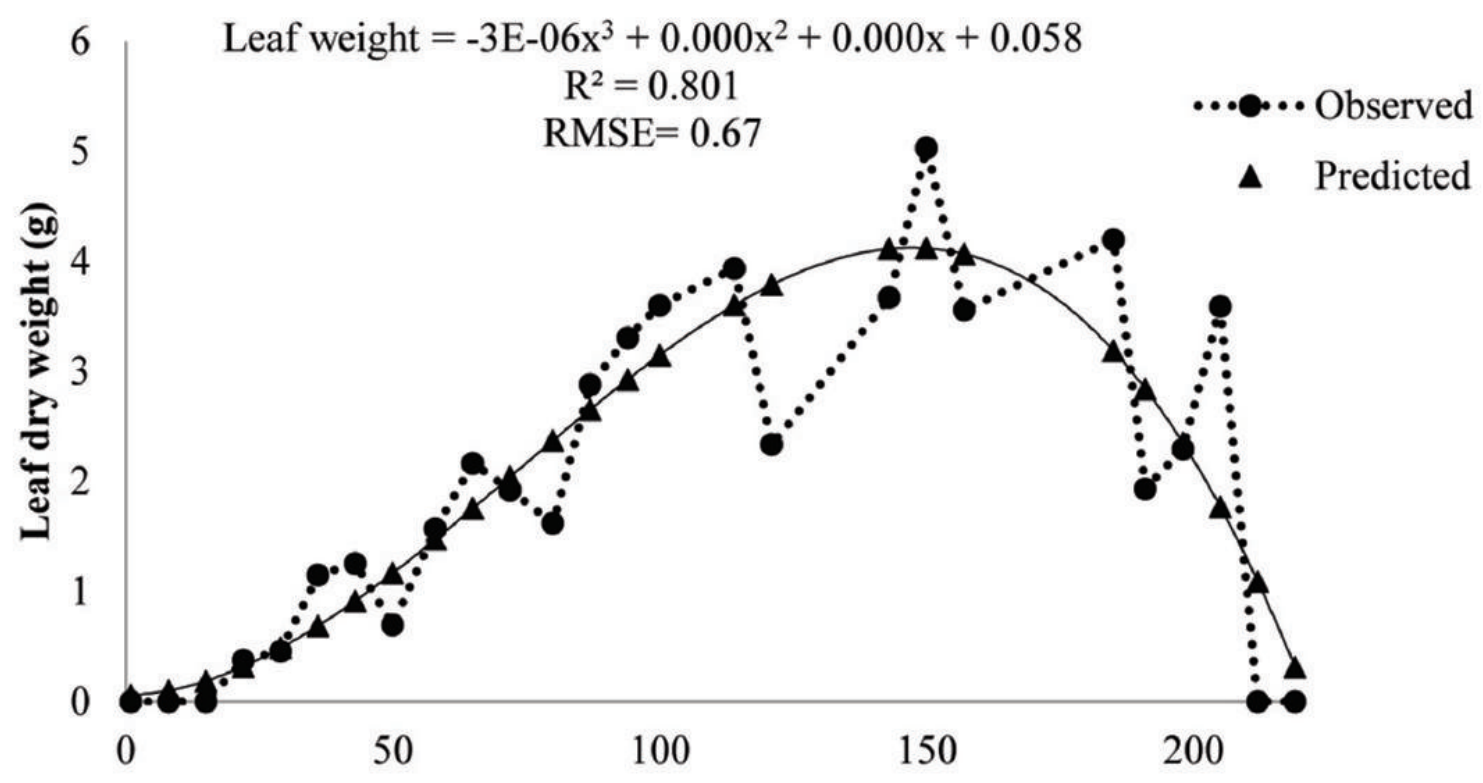

Days after growth

Fig. 6. Leaf dry weight changes during saffron growth cycle (October 8-May 10).

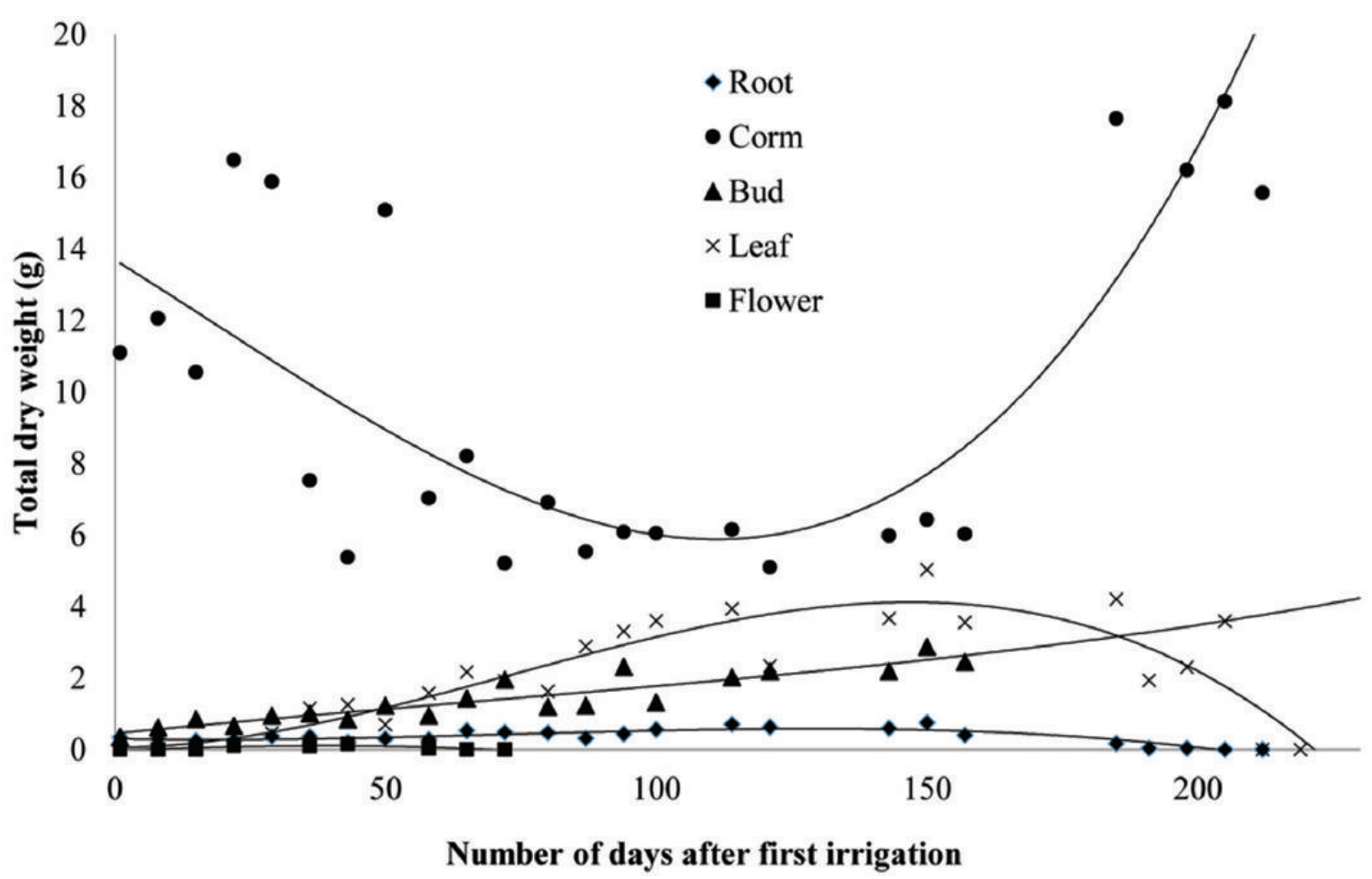

Fig. 10. Biomass partitioning trends during saffron growth cycle. 